\title{
Caixa de Atividades Diárias para Ratos ${ }^{1}$
}

\author{
Bruno César de Pinho Costa ${ }^{2}$ \\ Rubens Adair Costa Filho \\ Leonardo Marcus de Pinho Costa \\ Pontificia Universidade Católica de São Paulo
}

\begin{abstract}
RESUMO - Este trabalho apresenta um protótipo de caixa de condicionamento operante para ratos - batizada de Caixa de Atividades Diárias Para Ratos - que permite o registro, 24h por dia, de múltiplos operantes. O sujeito experimental pode ser remotamente monitorado (visto e ouvido em tempo real) por meio de uma webcam localizada na frente da caixa. Além disso, todas as funções do equipamento podem ser controladas remotamente via internet. Trata-se da primeira caixa experimental a reunir todas estas funções, ao menos no Brasil. Algumas sugestões de áreas de pesquisa em que o equipamento poderia ser utilizado são apresentadas.
\end{abstract}

Palavras-chave: caixa experimental, ambiente experimental complexo, monitoramento remoto, controle remoto

\section{Daily Activities Box for Rats}

\begin{abstract}
This work presents a prototype of an operant conditioning box for mice - named Daily Activities Box for Rats -, in which multiple operants can be recorded $24 \mathrm{~h}$ per day. The experimental subject can be monitored remotely (seen and heard in real time) by means of a webcam located in front of the box. Furthermore, all the equipment functions can be controlled remotely via internet. This is the first experimental box to gather all these functions, at least in Brazil. Some suggestions of areas of research in which the equipment may be used are presented.
\end{abstract}

Keywords: experimental box, complex experimental environment, remote monitoring, remote control

A partir do trabalho de Costa (2010), foi construído um novo protótipo de caixa de condicionamento operante para ratos em que múltiplos operantes podem ser registrados (para outras caixas experimentais similares, ver também Lucas, Timberlake \& Gawley, 1988; Lyons \& Cheney,1984; Mcintire, Lundervold, Calmes, Jones \& Allard, 1983; Mellgren, 1982; Sales, 2006; Timberlake \& Lucas, 1991). Esse equipamento recebeu o nome de Caixa de Atividades Diárias Para Ratos.

Nessa caixa, as respostas do animal (rato) são automaticamente registradas por intermédio de uma interface de controle conectada a um computador que, além de permitir o registro contínuo e completo, ao longo de 24 $\mathrm{h}$, das atividades diárias do sujeito experimental, também possibilita controle manual e automático/programado ${ }^{3}$ de todas as suas funções. É importante frisar que o registro contínuo e completo das atividades do sujeito ao longo de $24 \mathrm{~h}$ fornece ao experimentador o quadro mais completo possível da história de vida do sujeito experimental e, por isso, é tratado por Johnston e Pennypacker (1993, p. 116) como "claramente o padrão observacional ideal" - ver Anliker e Mayer (1956), Costa (2010), Díaz e Bruner (2007), Lucas, Timberlake e Gawley (1988), Petersen e Lyon (1978), Richter (1922), Skinner e Morse (1958), Timberlake e Lucas

1 Os autores dedicam este trabalho à memória da Profa. Dra. Tereza Maria de Azevedo Pires Sério (Téia) e agradecem à Deyse Costa, à Profa. Dra. Maria Virgínia de Carvalho e ao Prof. Dr. Lauro Naline por todo o suporte durante a construção deste equipamento.

2 Endereço para correspondência: Rua Cayowaá, n 777, ap 71, São Paulo, SP, Brasil, CEP: 05018000.E-mail: bruno_psic@yahoo.com.br
(1991) para acesso a experimentos que utilizam esse tipo de estratégia de registro, embora apenas nos trabalhos de Lucas et al. (1988), Timberlake e Lucas (1991) e Costa (2010), o registro contínuo e completo tenha sido utilizado em um ambiente experimental com múltiplos operantes.

A Caixa de Atividades Diárias para Ratos possibilita ao experimentador acompanhar remotamente o andamento dos experimentos por meio de uma webcam com visão noturna colocada na parte frontal da caixa (composta de acrílico). Isso permite - além de obter os registros quantitativos das atividades do sujeito por intermédio da caixa e de sua interface - observar e escutar, em tempo real, a partir de qualquer dispositivo que disponha de internet e do software Skype (programado para atender chamadas automaticamente), o que o sujeito experimental está fazendo a qualquer momento do dia (ou do ciclo de claro-escuro).

Além da possibilidade de monitorar remotamente o andamento dos experimentos (ver e ouvir o rato em tempo real), a caixa também pode ser controlada remotamente. Isso é realizado por intermédio de um software de controle remoto chamado Team Viewer (de acesso livre na internet ${ }^{3}$ ), o qual permite manipular qualquer variável experimental, bem como ter acesso a todos os dados que estão sendo registrados em tempo real pelo equipamento, podendo inclusive baixá-los

3 A caixa é controlada por um software desenvolvido pelos autores exclusivamente para estes fins. Por razões de espaço serão descritas as funções que a caixa pode executar sem menções pormenorizadas ao funcionamento do software. Para maiores informações sobre o software escrever para:bruno_psic@yahoo.com.br.

4 O programa pode ser encontrado no seguinte link: http://www.baixaki. com.br/download/teamviewer.htm 
a partir de qualquer dispositivo que disponha de acesso a internet.

O ambiente experimental da caixa dispõe de quatro barras e três luzes localizadas acima das barras, um comedouro que libera a ração em pelotas, dois bebedouros, uma roda de atividades, um disco circular de madeira preso a uma das paredes e uma campainha que pode ser programada para

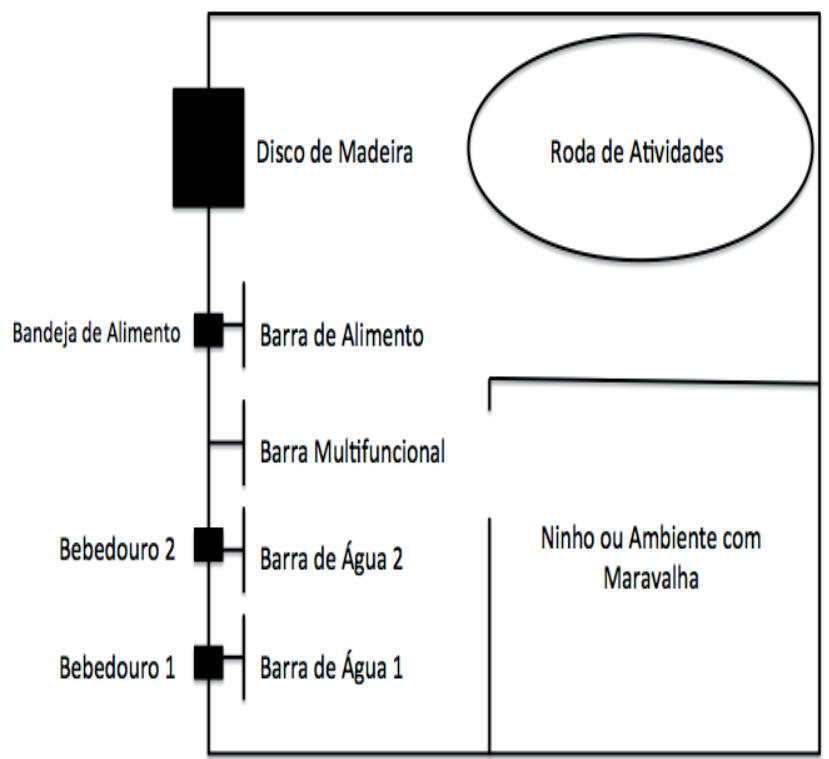

Figura 1. Desenho esquemático da caixa experimental. Estão ausentes, nesta planta, as luzes que se localizam acima de cada uma das barras, a luz do teto e os três sensores de movimento localizados também no teto.

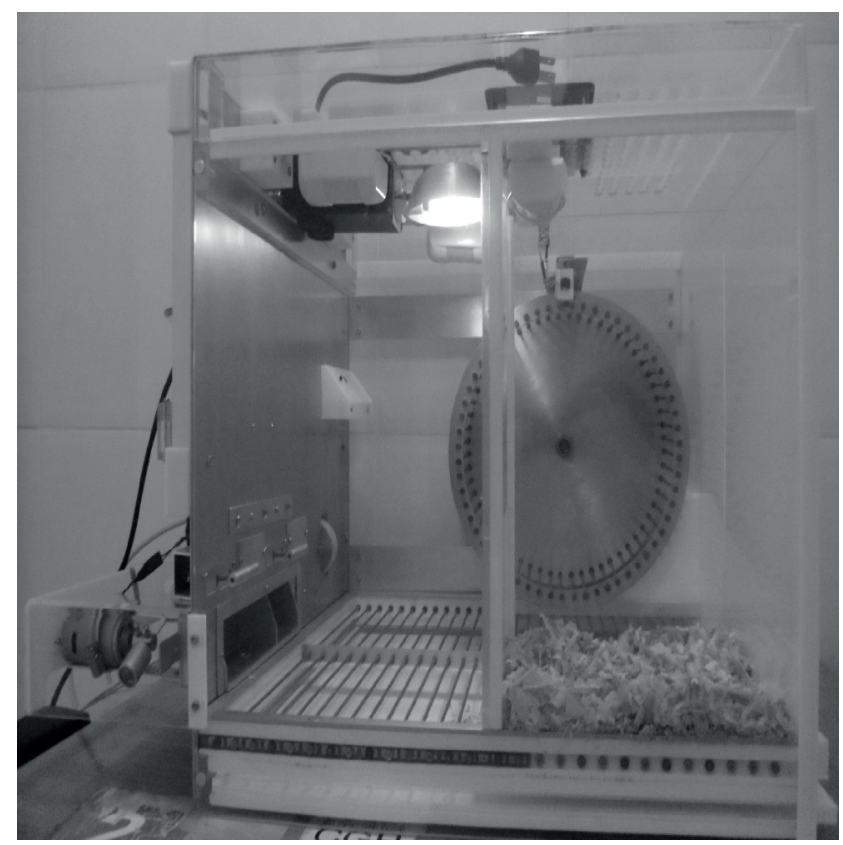

Figura 2. Foto da caixa batida de frente. Pode-se notar o painel das barras a esquerda e as três luzes do painel acima das barras. O disco de madeira está localizado ao lado das barras. Logo à frente, na direita da foto, podese observar o ninho e, mais ao fundo, a roda de atividades. Os sensores de movimento e a luz central se localizam no teto. Estão ausentes a barra multifuncional e a barra de liberação de água 2 . produzir 10 diferentes configurações de som (bips de duração programável, espaçados por 10 diferentes períodos de tempo, também programáveis), além de três sensores de movimento e uma lâmpada, estes últimos localizados no teto. O piso é composto de uma plataforma gradeada retrátil que possibilita a liberação de choque, sendo parte dela coberta por serragem (formando o ninho). As figuras 1 e 2 apresentam ilustrações do equipamento.

Os tipos de dispositivos da caixa podem ser enumerados e classificados da seguinte maneira:

Dispositivos de entrada - dispositivos que podem ser acionados por diferentes respostas do sujeito experimental: (1) barra de alimento, (2) barra multifuncional - ausente na Figura 2, (3) barra de água 1, (4) barra de agua 2 - ausente na Figura 2, (5) roda de atividades, (6) disco de madeira, (7) ambiente de maravalha ou ninho, e (8) sensores de movimento (três unidades localizadas no teto).

Por intermédio desses dispositivos, a caixa permite o registro dos seguintes tipos de atividades do sujeito: (1) número de pressões à barra de liberação de alimento, medidas por meio do número de fechamentos do contato de um microswitch; (2) número de pressões à barra de liberação de água 1 , medidas por meio do fechamento do contato de um microswitch; (3) número de pressões à barra de liberação de água 2 , medidas por meio do fechamento do contato de um microswitch; (4) número de pressões à barra multifuncional (que pode ser programada para diferentes funções, como ligar e desligar luzes, sons, etc.), medidas por meio do número de fechamentos do contato de um microswitch; (5) número de respostas em um disco de madeira (e.g., roer, morder, empurrar, puxar) que são medidas por meio do número de fechamentos do contato de qualquer um dos quatro microswitchs conectados ao aparelho; (6) número de voltas completas efetuadas na roda de atividade, medidas por um reedswitch que é acionado por meio de um imã acoplado à roda; (7) número de entradas e de saídas do ninho, indicado pelos sensores de movimento localizados no teto; (8) tempo de permanência em cada uma das entradas e saídas no ninho, também indicado pelos sensores de movimento do teto; e (9) número de acionamentos dos sensores de movimento, que oferece uma medida da atividade motora geral do sujeito ao longo do ambiente experimental.

Dispositivos de saida - dispositivos pelos quais o pesquisador pode produzir alterações no ambiente experimental: (1) luzes do painel 1, 2 e 3 - três lâmpadas de seis watts cada; (2) som - 10 diferentes configurações de som (bips de $1000 \mathrm{hz}$ de frequência e com duração programável, que podem ser espaçados por diferentes períodos de tempo), cujos acionamentos e desligamentos podem ser independentemente programados; (3) comedouro; (4) bebedouro 1; (5) bebedouro 2; (6) luz do teto - uma lâmpada de 20 watts que pode ser programada para diferentes intensidades de luz; e (7) choques elétricos, liberados pelo piso da caixa, sendo a duração e a amperagem do choque possíveis de serem definidas via programação.

O ambiente proporcionado por esse equipamento, associado ao registro contínuo e completo das atividades diárias do sujeito experimental, podem ser utilizados para diferentes áreas de pesquisa em Análise do Comportamento. O trabalho de Costa (2010), bem como o trabalho de 
doutorado do primeiro autor do presente texto (ainda em andamento) utilizam esse tipo de ambiente experimental e estratégia de registro para produzir conhecimento sobre operações motivadoras. Já Lucas et al. (1988) e Timberlake e Lucas (1991) pesquisaram sobre o comportamento adjuntivo. Mas esse tipo de ambiente e estratégia de registro permite a investigação de outros temas. Por exemplo, pode-se investigar os efeitos de diferentes drogas sobre diferentes atividades diárias do sujeito experimental ao longo dos dias, bem como observar as possíveis mudanças em seus padrões de atividade após a interrupção da administração das drogas. Seria possível também estudar a questão da suposta durabilidade dos efeitos da punição por muitos dias consecutivos, bem como seus possíveis efeitos sobre as demais respostas do sujeito experimental que nem sequer foram punidas. Os protocolos de cronic-mild-stress (CMS) poderiam ser aplicados aos sujeitos que vivem nesse ambiente e seria possível observar os efeitos do protocolo sobre um conjunto de atividades diárias do sujeito experimental que são continuamente registradas ao longo de muitos dias consecutivos, etc. Enfim, esse equipamento poderia ser utilizado em qualquer pesquisa que tenha o interesse de observar os efeitos de um conjunto de variáveis experimentais sobre mais de uma classe de respostas ao longo do tempo. Sua construção parece seguir um caminho apontado por Skinner (1938/1991) quando ele afirma,

Conforme o poder de análise vem crescendo, mais e mais comportamentos complexos vêm sendo estudados, sob contingências as quais se aproximam da sutileza e complexidade das contingências encontradas no mundo como um todo. Mais do que o organismo faz em qualquer dado momento é analisado. Múltiplos estímulos e múltiplas respostas compõem sistemas complexos de operantes concorrentes e encadeados. Experimentos podem levar semanas em vez da hora padrão do Comportamento dos Organismos. Ambientes especiais podem ser mantidos desde o nascimento. $\mathrm{O}$ aparato necessário para tudo isso é bem mais elaborado: simples relés, relógios e contadores tem dado lugar para circuitos solid-state e computadores. Todos esses avanços foram facilitados por uma formulação a qual enfatizou o comportamento em vez de estados e processos causais inferidos. (p. xv)

\section{Referências}

Anliker, J., \& Mayer, J. (1956). An operant technique for studying feeding-fasting patterns in normal and obese mice. Journal of Applied Physiology, 8, 667-670.

Costa, B. C. P. (2010). Estudos exploratórios sobre operações motivadoras (Unpublished master's thesis). Pontifícia Universidade Católica de São Paulo, São Paulo.

Díaz, F., \& Bruner, C. A. (2007). Comer y beber em ratas com libre acceso a la comida y al agua. Acta Comportamentalia, 15, 111-130.

Johnston, J. M., \& Pennypacker, H. S. (1993). Strategies and tactics of behavioral research (2a ed.). New Jersey, Estados Unidos: Lawrence Erlbaum Associates.
Lucas, G. A., Timberlake, W., \& Gawley, D. J. (1988). Adjunctive behavior of the rat under periodic food delivery in a 24-hour environment. Animal Learning \& Behavior, 16, 19-30.

Lyons, C. A., \& Cheney, C. D. (1984). Time reallocation in a multiresponse environment: Effects of restricting response classes. Journal of the Experimental Analysis of Behavior, 41, 279-289.

Mcintire K., Lundervold, D., Calmes, H., Jones, C., \& Allard, S. (1983). Temporal control in a complex environment: An analysis of schedule-related behavior. Journal of the Experimental Analysis of Behavior, 39, 465-478.

Mellgren, R. L. (1982). Foraging in a simulated natural environment: There's a rat loose in the lab. Journal of the Experimental Analysis of Behavior, 38, 93-100.

Petersen, M. R., \& Lyon, D. O. (1978). Schedule-induced polydipsia in rats living in an operant environment. Journal of the Experimental Analysis of Behavior, 29, 493-503.

Richter, C. P. (1922). A behavioristic study of the activity of the rat. Comparative Psychology Monographs, 1, 1-55.

Sales, T. M. (2006). Um estudo sobre as atividades nas quais sujeitos se engajam durante o intervalo entre respostas que produzem reforço (Unpublished master's thesis). Pontifícia Universidade Católica de São Paulo, São Paulo.

Skinner, B. F., \& Morse, W. H. (1958). Sustained performance during very long experimental sessions. Journal of the Experimental Analysis of Behavior, 1, 235-244.

Skinner, B. F. (1991). The behavior of organisms: An experimental analysis. Cambridge: Copley Publishing Group. (Trabalho original publicado em 1938)

Timberlake, W., \& Lucas, G. A. (1991). Periodic water, interwater interval, and adjuntive behavior in a 24-hour multiresponse environment. Animal Learning \& Behavior, 19, 369-380.

Recebido em 22.06.2012

Primeira decisão editorial em 31.03.2014

Versão final em 08.04.2014

Aceito em 24.04.2014 